\title{
An Individual Approach to Thrombolytic Therapy in Patients with Evolving Myocardial Infarction
}

\author{
M. L. Simoons, E. Boersma
}

In recent years different regimens for reperfusion therapy in evolving myocardial infarction have been developed: intravenous streptokinase, accelerated tPA and direct angioplasty. The life saving effect of thrombolytic therapy has been established in a number of randomized trials, most of which tested streptokinase 1.5 million units administered over $1 \mathrm{~h}$. The results have been summarized in the report of the fibrinolytic therapy trialists. In patients treated within $6 \mathrm{~h}$ after the onset of symptoms an overall treatment benefit of $28 \%$ has been observed, while a smaller benefit $(12.5 \%)$ can be achieved by treatment between 6 and $12 \mathrm{~h}$ after symptom onset. 2,3

Two studies showed no difference between streptokinase and alteplase or duteplase given without heparin or with delayed administration of subcutaneous heparin. ${ }^{4,5}$ In contrast, the GUSTO study clearly demonstrated improved survival (mortality reduction $18 \%$ ) by accelerated tPA, administered over $90 \mathrm{~min}$, with high dose intravenous heparin. ${ }^{6}$ The GUSTO angiographic substudy confirmed that a greater benefit by accelerated tPA was caused by higher early reperfusion rates obtained by that regimen, while later patency rates $(3 \mathrm{~h}$ or more after onset of therapy) were similar for the different regimens. 7,8

Three recent studies have shown more rapid reperfusion by direct angioplasty, associated with better survival compared with thrombolytic therapy. ${ }^{9-12}$ The proportion of patients with adequate (TIMI grade III) perfusion at various intervals after the onset of therapy is illustrated in Figure 1.

Unfortunately the more effective regimens (accelerated tPA versus streptokinase and direct angioplasty versus thrombolytic therapy) are also more expensive and more complex. Because of budgetary constrains it will often not be possible to provide the best (and most

Maarten L. Simoons, Eric Boersma, Thoraxcenter, BD 434, University Hospital Rotterdam, Dr. Molewaterplein 40, 3015 GD Rotterdam. The Netherlands.

Correspondence to Maarten L. Simoons, MD, Professor of Clinical Cardiology. expensive) therapy to all patients. In this paper we present a model which may help to allocate different modes of therapy to specific groups of patients with evolving myocardial infarction in a rational way.

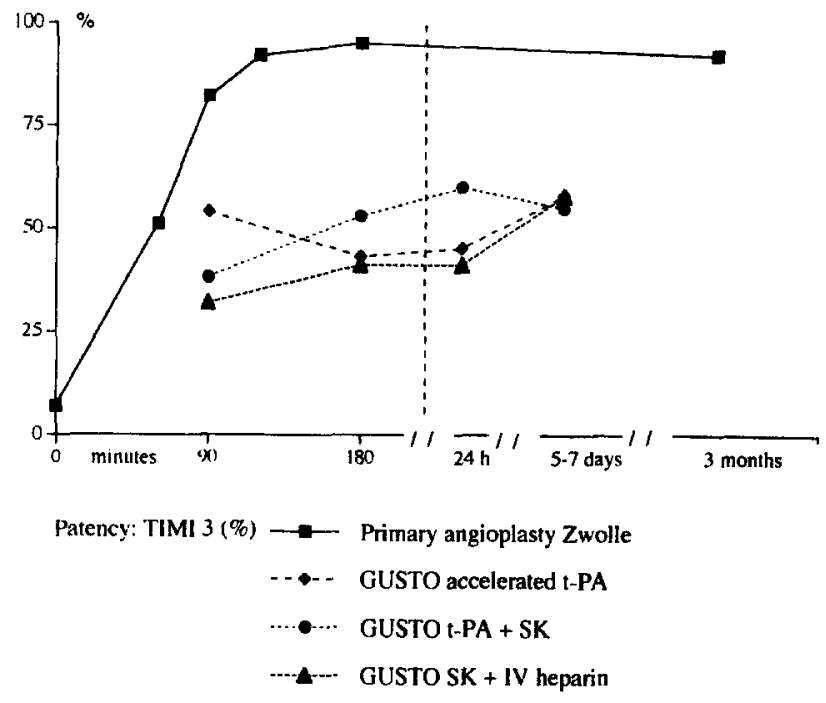

Fig. 1 Graphic display of Thrombolysis in Myocardial Infarction (TIMI) grade 3 flow immediately after randomization: comparison of the angiographic results from the Zwolle and GUSTO trials. The data on TIMI flow in the GUSTO trial were gathered from different patients, who were randomly assigned to angiography at different time intervals after start of therapy. GUSTO indicates the Global Utilization of Streptokinase and Tissue plasminogen activator for Occluded Coronary Arteries Study; tPA indicates tissue plasminogen activator; SK indicates streptokinase. From: Chapter 5, Thesis M.J. de Boer, 1994, p 128.

Currently available data indicate a proportional reduction of mortality by reperfusion therapy (compared with conventional treatment or placebo) and by accelerated tPA compared with streptokinase. ${ }^{1-6}$ Thus the greatest benefit in absolute terms (lives saved) will be achieved in patients with the greatest mortality risk. A model to predict early ( 1 year) mortality in different patient subgroups is presented in Figure 2. This model has 


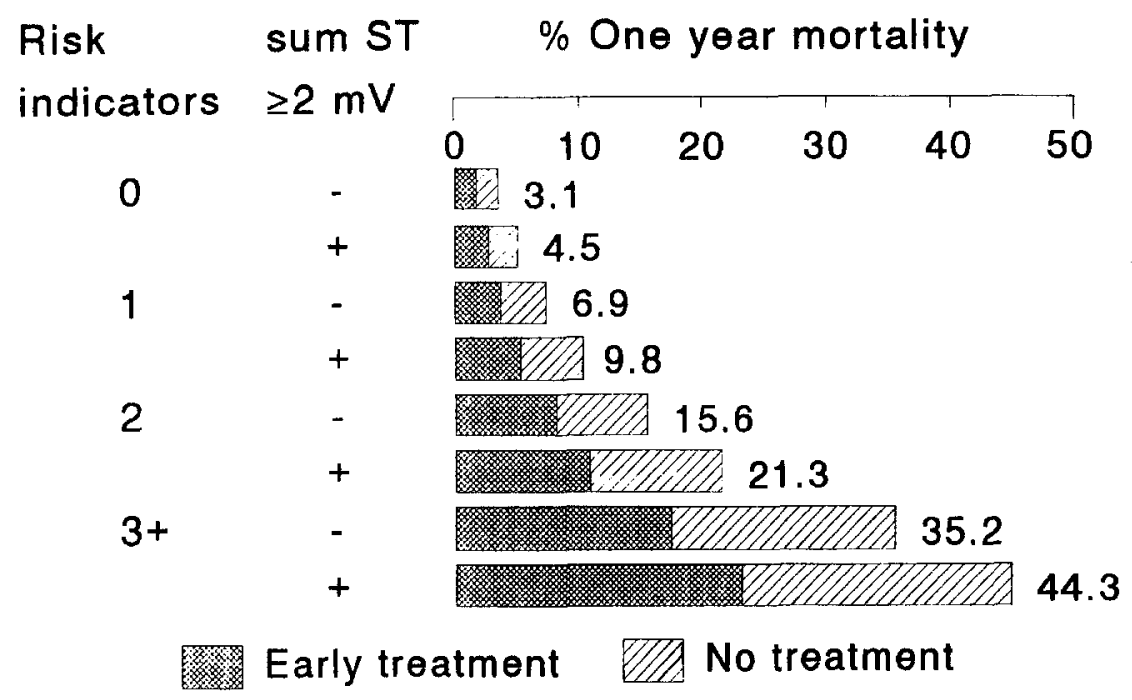

Fig. 2 Estimated probability of death without and with (early) reperfusion therapy. From top to bottom subgroups of patients are presented without or with one to three indicators for increased mortality risk: age $>60$ years, history of previous infarction, anterior location of infarction, inferior infarction with right ventricular involvement, presence of congestive heart failure, QRS duration $>120 \mathrm{~ms}$. In each of these four subgroups, patients are subdivided according to the extent of ST segment deviation (elevation and depression) in the combined 12 leads: $\geq$ or $<2 \mathrm{mV}$ ( $=20 \mathrm{~mm}$ on standard calibration).

Data derived from four studies as presented in reference 13 . Low mortality risk $(13.1-4.5 \%)$ in a subgroup of $25 \%$ of patients without risk indicators. Mortality risk $35-44 \%$ in a subgroup of $9 \%$ of patients with three or more risk indicators.

One year mortality without reperfusion therapy is indicated by the length of the bars. Early reperfusion therapy (within $3 \mathrm{~h}$ of symptom onset) will reduce mortality by $50 \%$, the remaining mortality is indicated by the dark portion of the bars, the number of patients saved is indicated by the light portion of the bars.

been derived by multivariable analysis using data from 4 different placebo controlled studies. ${ }^{13}$ In patients with a small infarct without additional risk indicators (a subgroup including $25 \%$ of patients enrolled in these trials) 1 year mortality will be less than $5 \%$. In contrast, mortality may be as high as $25 \%$ or greater in patients with multiple risk indicators (9\% of trial population).

In view of this gradient of benefit in different patient subgroups, and the gradient in efficacy of various treatment regimens it will be most appropriate to apply the most effective (most intensive and most expensive) therapy to patients where the greatest benefit may be expected. Furthermore, medical ethics imply that patients with similar expected benefit should receive the same treatment, irrespective of their financial or social status, and irrespective of their age. In order to apply this principle a yardstick must be developed to assess the expected benefit of various modes of reperfusion therapy, depending on the patients characteristics. With such yardstick patients can be ranked in order of the expected benefit, and patients groups with the greatest expected benefit may be allocated to more intensive (and more expensive) therapy while a less intensive (and less expensive) therapy may be provided to patients with a smaller expected benefit. The best outcome parameter for such yardstick would be the expected gain in life years after therapy.

\section{ESTIMATION OF THE EXPECTED GAIN IN LIFE YEARS BY REPERFUSION THERAPY}

The expected gain in lives may be computed in a two step approach. First, assessment of the life years gained in the first year after treatment for myocardial infarction and subsequently assessment of life expectancy of survivors.

The initial (1 year) gain in life years can be derived from the model presented in Figure 2. Subsequently, long term survival (after the first year) can be estimated using:

- Survival curves

- Survival tables of the normal reference population in various age groups. In The Netherlands, life expectancy in subjects at an average age of 55 years is 22.0 years, while this is 14.3 years and 8.4 years in subjects at an age of 65 and 75 years, respectively.

- Follow up data up to 5 or 10 years from trials with reperfusion therapy. These indicate that yearly mortality after myocardial infarction exceeds average yearly mortality in a population by approximately $1.5 \% .^{14,15}$

- Late mortality will continue to be greater in patients with extensive damage after a large infarction, and will be smaller in patients with preserved cardiac function after a limited infarct.

- In studies of cost efficacy analysis it is customary to give a higher weight to the near future compared to the more distant future. Thus future life years are discounted, usually with a rate of $5 \%$ per year. This discounting procedure also reflects the fact that early treatment outcome can be predicted more accurately than late outcome. In contrast, no value judgement is made comparing different age groups. 
Thus the next 5 years of a 70 year old (from 70 to 75 ) are given the same weight as the next 5 years of a 50 year old person (between 50 and 55 years). The higher mortality rate at advanced age is taken into account using the above mentioned specific population derived life expectancy figures.

The results of the analysis as described above are presented in the Table. A more extensive set of tables has been developed and is currently under evaluation in our institution as well as several other cooperating hospitals.

\section{INTRACRANIAL BLEEDING RISK}

Intracranial bleeding is infrequent in patients with myocardial infarction without thrombolytic therapy, while bleeding risk is increased with such therapy. Patients receiving standard streptokinase therapy have an intracranial bleeding risk of $0.5-1.0 \%$, while this risk is slightly higher in patients treated with accelerated tPA. 6.16 Through multivariable analysis of data from different trials the following risk factors for intracranial bleeding were identified: advanced age, hypertension at the time of hospital admission, low body weight, and use of alteplase compared with streptokinase. ${ }^{16}$ Furthermore, bleeding risk is increased in patients with previous cerebrovascular disease, and patients with a recent cranial trauma, for example those who fainted from arrhythmias during the infarct. In larger trials, the total risk of stroke after thrombolytic therapy was similar to the risk of stroke without such therapy. In fact, the risk of embolic stroke is reduced by thrombolytic therapy as a result of limitation of infarct size and the anticoagulant effect of the thrombolytic agents. The reduced embolic stroke rate compensates the increased incidence of intracranial hemorrhage.

It should be appreciated that the benefit of thrombolytic therapy in most patients far outweighs the intracranial bleeding risk. Similarly, the benefit of therapy with accelerated tPA over streptokinase is approximately 10 fold greater than the increased bleeding risk by $\mathrm{PA}^{6}$ Only in patients with a small infarct an increased bleed- ing risk may outweigh the possible benefits of thrombolytic therapy. Also, the increased risk should be taken into account in patients at advanced age with multiple bleeding risk indicators.

\section{ALLOCATION OF RESOURCES}

Data such as presented in Table provide an objective measure of the expected benefit of reperfusion therapy. Thus a ranking of patients with different levels of benefit is provided. Still, in different hospital environments decisions must be made which threshold levels to apply for various modes of therapy. Such decisions should be based on the availability of resources and funds. At the Thoraxcenter we have elected to provide direct angioplasty to approximately $10 \%$ of patients: those with the greatest expected benefit, particularly if they are at increased risk for intracranial hemorrhage. ${ }^{16}$ Accelerated tPA and intravenous streptokinase will be applied in approximately equal numbers of patients, while no reperfusion therapy will be provided to a small subgroup of patients in whom benefit would be negligible anyhow. Other centers may elect different allocation of resources and decide to use accelerated IPA (the more effective treatment) more frequently than streptokinase, or they may elect to use angioplasty in a greater proportion of patients. Still the same measure can be used (as presented above) applying different threshold values.

\section{MEDICAL JUDGEMENT PREVAILS}

It should be appreciated that the models to develop the decision tables have a limited accuracy. The model provides a guideline for medical management, but the physician may decide on other treatment, particularly in patients with characteristics which have not been included in the model. For example thrombolytic therapy should be avoided in patients with recent cranial trauma, because of increased intracranial bleeding risk. In such patients direct angioplasty would be appropriate, in spite of modest expected treatment benefit, if such therapy can be made available at short notice. Still, in our experience the decision tables are of great help to physicians who

Table Tailored reperfusion therapy - life expectancy (years)

\begin{tabular}{|c|c|c|c|c|}
\hline \multicolumn{2}{|c|}{ Patient characteristics } & \multirow{2}{*}{$\begin{array}{c}\text { No } \\
\text { therapy }\end{array}$} & \multirow[t]{2}{*}{$\begin{array}{c}\text { Reperfusion } \\
\text { at } 4 \mathrm{~h}\end{array}$} & \multirow[t]{2}{*}{$\begin{array}{l}\text { Years } \\
\text { added }\end{array}$} \\
\hline $55 \mathrm{yr}$ & no MI & & & \\
\hline & small MI & 16.1 & 16.1 & \\
\hline & large MI & 6.2 & 8.4 & 2.2 \\
\hline \multirow[t]{3}{*}{$65 \mathrm{yr}$} & no $\mathrm{MI}$ & 14.3 & & \\
\hline & small MI & 10.7 & 10.8 & 0.1 \\
\hline & large MI & 4.7 & 5.6 & 1.2 \\
\hline
\end{tabular}

Life expectancy (years) in patients aged 55 (top panel) or 65 (bottom panel) years without myocardial infarction with a small infarct, and with extensive infarction (anterior infarction with heart failure and extensive ST-segment elevation). No therapy = life expectancy without reperfusion therapy. In addition life expectancy with reperfusion therapy at $4 \mathrm{~h}$ is indicated as well as the number of life years added by reperfusion therapy 
often must make decisions on the allocation of therapy with little time for reflection under difficult circumstances in the midst of the night.

\section{REFERENCES}

1. Fibrinolytic Therapy Trialists (FTT) Collaborative Group. Indications for fibrinolytic therapy in suspected acute myocardial infarction: collaborative overview of early mortality and major morbidity results from all randomized trials of more than 1000 patients. N Engl J Med 1994; 343: 311 -322.

2. LATE Study Group. Late Assessment of Thrombolytic Efficacy (LATE) study with alteplase 6-24 hours after onset of acute myocardial infarction. N Engl J Med 1993; 342: 759-766.

3. EMERAS (Estudio Multicéntro Estreptoquinasa Repúblicas de América del Sur) Collaborative Group. Randomized trial of late thrombolysis in patients with suspected acute myocardial infarction. N Engl J Med 1993; 342: 767-772.

4. Maggioni AP. Franzosi MG, Santoro E, White H, van de Werf F, Tognoni $G$, the Gruppo Italiano per lo Studio della Sopravvivenza nell'Infarto Miocardico II (GISSI-2) and the International Study Group. Cerebrovascular events after myocardial infarction: analysis of the GISSI trial. N Engl J Med 1992;327: 1-6.

5. ISIS-3 (Third International Study of Infarct Survival) Collaborative Group. ISIS-3: a randomized comparison of streptokinase vs tissue plasminogen activator vs anistreplase and of aspirin plus heparin vs aspirin alone among 41299 cases of suspected acute myocardial infarction. N Engl J Med 1992: 339: 753-770.

6. GUSTO Investigators. An international randomized trial comparing four thrombolytic strategies for acute myocardial infarction. $\mathrm{N}$ Engl J Med 1993; 329: 673-682.

7. GUSTO Angiographic Investigators. The effects of tissue plasminogen activator, streptokinase, or both on coronary-artery patency, ventricular function, and survival after acute myocardial infarction. N Engl J Med 1993: 329; 1615-1622.

8. Baardman T, Hermens WT, Lenderink $T$ et al. Differential effects of tissue plasminogen activator and streptokinase on infarct size and on rate of enzyme release are explained by $90 \mathrm{~min}$ infarct related artery patency. The GUSTO enzyme study. Submitted for publication.

9. de Boer MJ, Suryapranata H, Hoorntje JCA et al. Limitation of infarct size and preservation of left ventricular function after primary coronary angioplasty compared with intravenous streptokinase in acute myocardial infarction. Circulation 1994: 90: 753-761.

10.Grines CL, Browne KF, Rothbaum MJ, Stone GW, O'Keefe J, Overlie P, Donohue B, Chelliah N, Timmis GC, Vlietstra RE, Strzelecki M, Puchrowicz-Occhocki S, O'Neill WW, for the Primary Angioplasty in Myocardial Infarction Study group. A comparison of immediate angioplasty with thrombolytic therapy for acute myocardial infarction. N Engl J Med 1993; 328 : 673-679.

11. Gibbons RJ, Holmes DR, Reeder GS, Bayley KR, Hopfenspirger MR, Gersh BJ. Immediate angioplasty compared with the administration of a thrombolytic agent followed by conservative treatment for myocardial infarction. N Engl J Med 1993; 328: 685-691.

12. O'Neill WW, de Boer MJ, Gibbons RJ et al. Chapter 8: Data from three prospective randomized clinical trials of thrombolytic versus angioplasty therapy of acute myocardial infarction. Preliminary results from a pooled analysis. In: Thesis M.J. de Boer, September 21, 1994, pp 166-171.

13. Simoons ML, Arnold AER. Tailored thrombolytic therapy. Circulation, 1993; 88: 2556-2564.

14. Simoons ML, Vos J, Tijssen JGP et al. Long-term benefit of early thrombolytic therapy in patients with acute myocardial infarction: 5 year follow up of a trial conducted by the Interuniversity Cardiology Institute of the Netherlands. J Am Coll Cardiol, 1989; 14: 1609-1615.

15. Lenderink T. Simoons ML, van Es GA, van de Werf F, Verstraete $M$ for the European Cooperative Study Group. Benefit of thrombolytic therapy is sustained throughout five-years, and is related to TIMI perfusion grade 3 but not grade 2 flow at discharge. Submitted for publication.

16. Simoons ML, Maggioni AP, Knatterud G et al. Individual risk assessment for intracranial hemorrhage during thrombolytic therapy. Lancet, 1993; 342: 1523-1528. 